\title{
SOME POSSIBLE CAUSES FOR RECENT VARIATIONS OF PATAGONIAN GLACIERS
}

\author{
(Abstract) \\ by \\ Renji Naruse \\ (Institute of Low Temperature Science, Hokkaido University, Sapporo 060, Japan) \\ and \\ Masamu Aniya \\ (Institute of Geoscience, University of Tsukuba, Ibaraki 305, Japan)
}

The Patagonian glaciers located in the southern part of the Andes between $46^{\circ} 30^{\prime} \mathrm{S}$ and $51^{\circ} 30^{\prime} \mathrm{S}$ are characterized by typical temperate conditions of heavy precipitation, rapid ice flows and high melting rates. During the austral summers of 1983-84 and 1985-86, field studies were made of the ice flow, heat balance and morphology of several glaciers in Patagonia. Coupled with aerial photographic surveys, these revealed that most glaciers had retreated extensively in the recent years, a maximum being $200 \mathrm{~m} \mathrm{a}^{-1}$ at San Rafael Glacier from 1974 to 1986. The lower part of Soler Glacier had thinned by a rate of $5.2 \mathrm{~m} \mathrm{a}^{-1}$ from 1983 to 1985 .

This paper presents three possible mechanisms to explain the large variation of temperate glaciers during the last decade, based on analyses of mass balance and dynamics of Patagonian glaciers:

(1) The annual melting rate was estimated at about $10-15 \mathrm{~m} \mathrm{a}^{-1}$ in water equivalent over the ablation area (from 350 to $1350 \mathrm{~m}$ a.s.1.) of Soler Glacier. Monthly mean air temperature in the coldest season (June through August) was estimated at about $0^{\circ}-4^{\circ} \mathrm{C}$ near the termini of most glaciers in Patagonia. That temperature coincides with an air temperature which is critical for solid or liquid precipitation. The difference in the surface albedo, that is, $0.7-0.8$ for new snow and $0.4-0.55$ for bare ice $(0.1-0.2$ for debris-covered ice), results in different melting rates. Hence, a slight change in air temperature should cause an enhanced change in ice thickness by a positive feedback mechanism.

(2) The flow velocity was measured or estimated and was found to change daily and seasonally by factors of 3 to 5 at Soler Glacier. The large flow velocity variation was attributed to difference in the basal sliding velocity. Consequently, a change in the amount of subglacial water or the structure of the basal water system should cause a large change in the ice flow, which in turn results in a retreat or an advance of the glacier-like "mini-surge".

(3) Frequent fluctuations of calving glaciers (e.g. San Rafael and Pio XI glaciers) have been much reported; however, information on the position of the grounding lines is very scarce. The advance or retreat of the glacier front may possibly have been affected by that of the floating terminus. The rate of calving from the ice tongue or spreading of ice shelves should mainly be controlled by the melting rate of ice in the water and by the mechanical properties of ice, and these factors are not directly related to climatic change or the surge phenomenon.

\section{RADIATION INTERACTIONS BETWEEN CLOUD AND SNOW AND ICE MASSES}

\section{(Abstract)}

by

Tetsuo Ohata

(Water Research Institute, Nagoya University, Nagoya 464, Japan)

Solar radiation is one of the most important meteorological components in the heat balance of the glaciers and other snow and ice masses. Observed solar radiation values are generally discussed in relation to altitude, landform, geographical position of the observation point and cloud. However, as surface of snow and ice masses possess high albedo, the surface global solar radiation on snow and ice masses usually shows higher value than surrounding ground which is low albedo, due to multiple reflection between surface and cloud. This is an important factor in determination of solar radiation on snow and ice masses. When this process is prominent, surface global solar radiation will depend on the size of the snow and ice masses. This process will be investigated in two parts. One is the presentation of radiation data taken on an ice cap and surrounding ground in the northwestern Tibetan plateau. Observations show that mean daily global solar radiation was $26 \%$ higher on the ice cap than on the ground: especially on cloudy days this value exceeded $50 \%$. The second is collaboration of radiation data on snow and ice masses of previous studies: those data will be discussed from the above point of view. The size effect of snow and ice masses on surface solar radiation will be stressed. 